\title{
Estudo do desenvolvimento urbano da bacia hidrográfica do Rio Ponte Grande, em Lages/SC
}

A crescente urbanização e industrialização das cidades, aliada a uma visão econômica e favorável a minorias, fez com que diversas pessoas se dirigissem para áreas periféricas, com infraestrutura precária. Realizar estudos e monitoramento quanto a ocupação do solo faz com que o planejamento urbano seja regrado, com enfoque na preservação e na qualidade de vida da população. O presente estudo objetivou-se analisar o uso e ocupação do solo na bacia hidrográfica do rio Ponte Grande, área urbana do município de Lages, em Santa Catarina, utilizandose de imagens de satélite TM-Landsat 5 e 8 , ao longo dos últimos 35 anos. 0 acesso às imagens foi possível acessando-se o catálogo do Serviço Geológico dos Estados Unidos e o processamento das mesmas foi executado no software ENVI ${ }^{\oplus}$ 4.7. Para a identificação das Áreas de Preservação Permanente (APP's) utilizou-se o software ArcGis ${ }^{\circledR} 10.1$, com integração de dados para a geração dos mapas. As classes identificadas para realizar a confecção do mapa e posterior estudo foram: floresta nativa, reflorestamento, campo, área urbana, corpos d'água, solo exposto e agricultura. Após análise da ocupação, realizou-se o diagnóstico populacional, utilizando dados do IBGE correspondentes à renda e ao número de pessoas por setor censitário. O software $\mathrm{ArcGis}^{\oplus} 10.1$ foi usado, com a ferramenta "selecionar por localização", para realizar a intersecção dos dados entre a bacia hidrográfica e os setores, e após inclusão das edificações. Verificouse, a crescente substituição das classes campo por reflorestamento com fim comercial e expansão urbana, que ocupa o maior percentual de classe, com 41,73\% em 2019. A classe correspondente a reflorestamento teve um crescimento expressivo, perpassando de 0,18\% em 1984 para 5,32\% em 2019. Com relação as APP's, essas foram sendo ocupadas e deterioradas, tendo pequenas parcelas resguardadas, localizadas em áreas com alta declividade e em áreas de cabeceiras. Muitas edificações são precárias, sem o mínimo do que é preceituado constitucionalmente e esse fato está inteiramente ligado ao fato de a renda per capta da população residente na área de estudo estar entre $1 / 4$ e 2 salários mínimos. Além da precariedade das edificações e do acesso à infraestrutura urbana, observa-se que 1313 edificações estão situadas em área de muito alto risco a eventos hídricos de inundação. Com a análise dos resultados fica evidente a necessidade de planejamento urbano em áreas periféricas, para que exista consciência ambiental, uso sustentável da terra e melhoria na qualidade de vida da população.

Palavras-chave: Ocupação do solo; Bacia hidrográfica; Vulnerabilidade; Planejamento urbano; Desenvolvimento sustentável.

\section{Study of the urban development of the hydrographic basin of the Ponte Grande River, in Lages/SC} \begin{abstract}
The growing urbanization and industrialization of cities, combined with an economic and minority-friendly vision, has led several people to move to peripheral areas with precarious
infrastructure. Carrying out studies and monitoring regarding land occupation causes urban planning to be ruled, focusing on preservation and quality of life of the population. This study infrastructure. Carrying out studies and monitoring regarding land occupation causes urban planning to be ruled, focusing on preservation and quality of life of the population. This study
aimed to analyze land use and occupation in the Ponte Grande River basin, an urban area in the municipality of Lages, Santa Catarina, using TM-Landsat 5 and 8 satellite images from the last aimed to analyze land use and occupation in the Ponte Grande River basin, an urban area in the municipality of Lages, Santa Catarina, using TM-Landsat 5 and 8 satellite images from the last
35 years. It was possible to obtain the images by accessing the U.S. Geological Survey catalog, and their processing was made utilizing ENVI ${ }^{\oplus} 4.7$ software. ArcGis 10.1 software was used for the identification of Permanent Preservation Areas (PPAs), with data integration in order to generate maps. The classes identified to generate the map and the further study were native forest, reforestation, field, urban area, water bodies, exposed soil and agriculture. After analyzing the occupation, a population diagnosis was made using data from IBGE corresponding to the income and number of people per census sector. Software $\operatorname{ArcGis}^{\circledR} 10.1$ was used, with the tool "select by location", to perform the intersection of data between the watershed and the sectors, and after the inclusion of the buildings. It was verified a growing substitution of fields by reforestation for commercial purposes and urban expansion, which occupies the highes class percentage with $41.73 \%$ in 2019. The class corresponding to reforestation had an expressive growth, going from 0.18\% in 1984 to $5.32 \%$ in 2019. The PPAs were occupied and requiremen, this is ention buildings and access to urban infrastructure, it can be observed that 1313 buildings are in areas of very high risk of flood events. With the analysis of the results, the need for urban planning in peripheral areas becomes evident, in order to create environmental awareness, sustainable land use and improvements in the quality of life of the population.
\end{abstract}

Keywords: Land occupation; Hydrographic basin; Vulnerability; Urban planning; Sustainable development.

Topic: Engenharia Ambiental

Reviewed anonymously in the process of blind peer.
Received: 03/01/2021

Approved: 28/01/2021
Mayara Rafaeli Lemos (iD)

Universidade do Estado de Santa Catarina, Brasil

http://lattes.cnpq.br/7642263124693032

http://orcid.org/0000-0002-8312-2374

may_rafaeli@hotmail.com

Valter Antonio Becegato (iD

Universidade do Estado de Santa Catarina, Brasil

http://lattes.cnpq.br/3196823526572670

http://orcid.org/0000-0002-6850-2846

valter.becegato@udesc.br

Vitor Rodolfo Becegato

Universidade do Estado de Santa Catarina, Brasil

http://lattes.cnpq.br/7642634231071974

vitorvrb92@gmail.com

DOI: 10.6008/CBPC2179-6858.2021.001.0029
Daniely Neckel Rosini (iD)

Universidade do Estado de Santa Catarina, Brasil

http://lattes.cnpq.br/1290138248832119

http://orcid.org/0000-0001-9873-6750

danielybio@hotmail.com
Referencing this:

LEMOS, M. R.; BECEGATO, V. A.; BECEGATO, V. R.; ROSINI, D. N.. Estudo do desenvolvimento urbano da bacia hidrográfica do Rio Ponte Grande, em Lages/SC. Revista Ibero Americana de Ciências Ambientais, v.12, n.1, p.347-361, 2021. DOI: http://doi.org/10.6008/CBPC2179-6858.2021.001.0029 


\section{INTRODUÇÃO}

As mudanças no espaço urbano, pelo desenvolvimento urbano, impactam as relações entre os componentes físicos, químicos, biológicos e sociais, influenciando no surgimento e/ou agravamento de fenômenos, como inundações, alagamentos e ilhas de calor (CHEN et al., 2006; MORUZZI et al., 2007; GARZUZI et al., 2010; SOUZA, 2013; LU et al., 2016).

As frequentes alterações no meio tornam o mesmo enérgico e esse carácter extremamente dinâmico do ambiente faz com que sejam necessárias informações detalhadas e que essas sejam repassadas com frequência, para se ter o real conhecimento da distribuição espacial e, assim, controle sobre a ocupação do espaço (FRANZONI et al., 2002; CUNHA et al., 2011; NEWBOLD et al., 2015).

O método comumente utilizado para realizar o monitoramento e, posterior, gestão da ocupação urbana é a análise das variações e distribuição da cobertura do solo para que assim tenha-se maior conhecimento sobre ocupação e estabeleçam-se relações entre as decisões políticas, ações regulatórias e o uso da terra (YANG et al., 2002; WENG et al., 2006; BONTEMPS et al., 2012; YANG et al., 2013; GRECCHI et al., 2014).

Ter o conhecimento de todos os processos dos sistemas ambientais é ter a possibilidade de prever os desequilíbrios, sejam esses decorrentes de fatores naturais ou resultantes de ações antrópicas (CÂMARA et al., 2001; CORDEIRO et al., 2014). Assim, utilizam-se imagens de satélite, para grandes áreas, facilitando a análise dos dados e entendimento dos mesmos (PRINA et al., 2011; LAMCHIN et al., 2016).

O mapa de uso do solo informa sobre os principais elementos estruturais que compõem a paisagem, serve como um referencial para se avaliar o estado atual das superfícies, no sentido de auxiliar o planejamento da ocupação, com o objetivo de coibir a ocupação em áreas destinadas a preservação e degradação ambiental. Desse modo é possível identificar e quantificar as áreas sensíveis e preservá-las (SANTOS, 2004; ALMEIDA, 2007; ELLIS et al., 2013; MARCHETTI et al., 2014; CORONA, 2016).

Utilizam-se de tecnologias espaciais para a obtenção de dados de terreno de forma repetitiva e sinóptica para auxiliar na investigação dos recursos naturais. Os sensores orbitais geram informações constantes e periódicas, que garantem a fiscalização do uso do solo (VIEIRA, 2011; ZHU et al., 2016). O sensoriamento apresenta grande porção de dados, sendo georreferenciados, em diversas escalas e em imagens digitais. Esses, atuais e contínuos, favorecem no planejamento e gestão urbana, na geologia, na agricultura (NOVO, 2008; LIMA et al., 2014; MACEDO et al., 2018).

No presente estudo efetuou-se uma análise da ocupação do solo na bacia hidrográfica do rio Ponte Grande, situada na cidade de Lages, SC, em área inserida no vetor de crescimento do município. A bacia do rio Ponte Grande é prioritariamente urbana e está ocupada quase que em sua totalidade, estando junto à foz do rio Caveiras, sendo cenário de desastres hidrológicos por inundação, enxurrada e alagamento e, portanto, é área de interesse especial.

A unidade territorial utilizada é bacia hidrográfica, por se tratar de um sistema natural delimitado geograficamente e de fácil caracterização, tendo essa delimitação aceitação mundial e ser o local adequado 
para propor planejamento e monitoramento ambiental (NASCIMENTO et al., 2008; ALVES, 2012; SOUZA, 2013).

A bacia hidrográfica objeto desse estudo está exposta a diversos impactos ambientais, em razão de ter sido ocupada de forma desordenada, sem quaisquer proteção e manutenção do meio, não haver rede de saneamento e, algumas vezes, até rede pluvial. Esses fatores influenciam diretamente a qualidade ambiental e a qualidade de vida da população, pois a poluição no local tem aumentado a cada ano. Destaca-se, ainda, sua importância em relação ao crescimento da cidade, visto que, em decorrência das características, relevo e proximidade com a área urbana consolidada, a tendência é que a expansão se dê nessa direção.

Diante disso, apresenta-se uma análise quanto ao uso e ocupação do solo na bacia hidrográfica do rio Ponte Grande, no ínterim de trinta e cinco anos, utilizando-se de técnicas de sensoriamento remoto e geoprocessamento em ambiente de SIG, com o objetivo de verificar como essa ocupação se deu e quais os fatores ambientais envolvidos nessa área, suas carências e deficiências, para atentar os gestores públicos quanto o processo de expansão e que esse se dê de forma ordenada, não prejudicando o meio. Como complementação do contexto da referida bacia, fez-se uma análise da população residente na área de estudo, com dados do censo do IBGE de 2010, em ambiente SIG, para melhor compreensão da questão cultural e ambiental vivida na bacia.

\section{MATERIAIS E MÉTODOS}

A área objeto deste estudo é a bacia hidrográfica do rio Ponte Grande, localizada ao município de Lages, região serrana do estado de Santa Catarina, no sul do Brasil (Figura 1), inserida entre as coordenadas X 570605.96 metros e Y 6926592.68 metros, com altitude média de 938 metros e área total de 2.722,35 ha. O curso principal do rio possui uma extensão de 14,3 km e na bacia existem 23 nascentes e 26 confluências (OLIVEIRA, 2015). A referida bacia está inserida tanto na área urbana, quanto na rural, perpassando por 21 bairros: da Várzea, Popular, São Miguel, Ferrovia, Caravágio, Coral, Penha, Santa Maria, Ponte Grande, Jardim Panorâmico, Gethal, São Sebastião, Vila Mariza, da Bates, da Chapada, Dom Daniel, Conta Dinheiro, Guarujá, Pisani, Jardim Celina e do Tributo (LAVNITCKI, 2018).

De acordo com a classificação de Köppen-Geiger, o clima da região é Cfb, mesotérmico, com verões brandos e precipitações pluviais bem distribuídas (ALVARES et al., 2013). A média anual da temperatura do ar no município de Lages varia entre $11^{\circ} \mathrm{C}$ e $21^{\circ} \mathrm{C}$, tendo as máximas nos meses de janeiro e fevereiro, correspondentes a estação de verão, e as mínimas em junho, mês da estação inverno. Já a precipitação anual média está em torno dos 1600 mm (CAMPOS et al., 2019).

O relevo apresenta-se de forma variada, entre plano a suavemente ondulado, com picos de maior elevação. Quanto à formação vegetal, predomina-se a presença de campos e Floresta Ombrófila Mista. O rio Ponte Grande está inserido, principalmente, na área urbana do município de Lages, sendo um afluente importante do rio Caveiras, o qual contempla a segunda maior bacia hidrográfica do rio Canoas, esse tributário do rio Uruguai (RAFAELI NETO et al., 2013). 


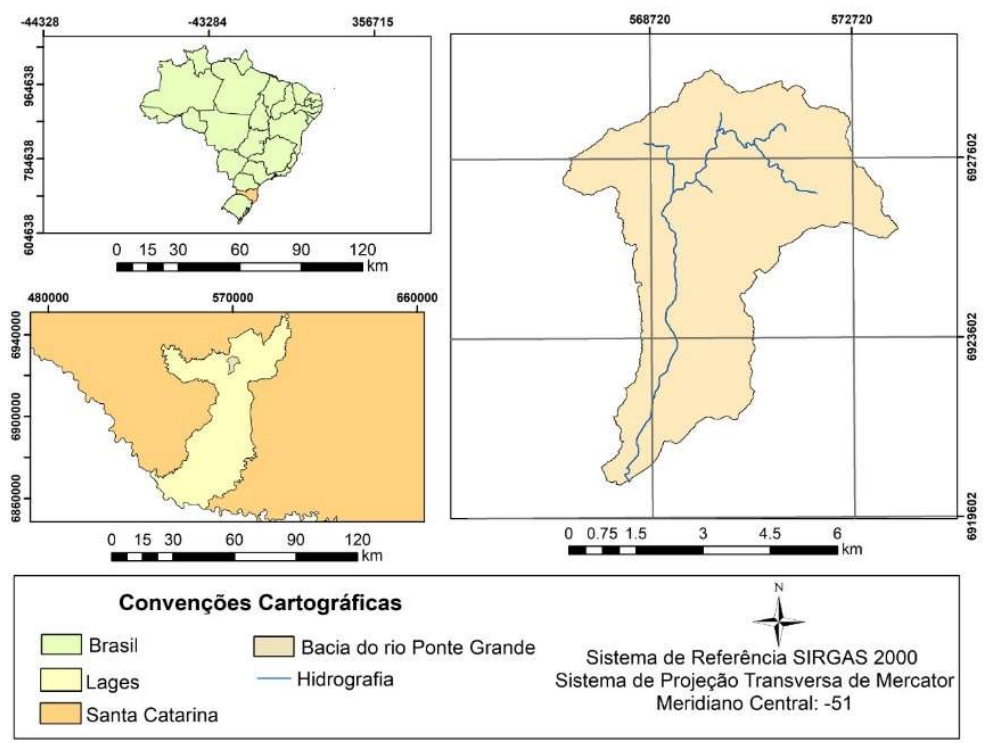

Figura 1: Mapa de localização da bacia hidrográfica do rio Ponte Grande - município de Lages-SC.

O presente estudo foi produzido a partir de Ortofotos, Modelo Digital de Terreno (MDT) e imagens orbitais, sendo aquelas oriundas do aerolevantamento do estado de Santa Catarina pela Secretaria de Desenvolvimento Econômico e Sustentável (SDS) do período compreendido entre os anos de 2010 a 2012. Já as imagens orbitais são oriundas do catálogo de imagens do Serviço Geológico dos Estados Unidos (USGS). A resolução espacial das Ortofotos é de $39 \mathrm{~cm}$, com escala de 1:10.000 e são provenientes de uma junção de fotos aéreas. Quanto ao MDT, o mesmo possui resolução espacial de 1 metro e pixel de 0,4 metros, formados da restituição aerofotogramétrica para os anos de 1984 até 2013. O MDT utilizado para os anos de 2017 e 2019 possui resolução espacial de 3 metros. A rede hidrográfica é originária da SDS e possui escala de 1:10.000. As imagens digitais são do mapeador temático (TM) dos satélites Landsat 5 com 7 bandas espectrais e Landsat 8 com 11 bandas, cujas resoluções são de 15 metros.

Para tratamento dos dados, utilizou-se o software ENVI ${ }^{\circledR}$ versão 4.7. Para confecção dos mapas de uso da terra atualizados, entre os anos de 2017 e 2019 foram aplicadas as técnicas de classificação supervisionada de cenas multiespectrais do sensor orbital Landsat 8, com datas de 22 de novembro de 2017 e 19 de novembro de 2019. Utilizou-se do Manual Técnico de Uso da Terra (IBGE, 2013) para definição das classes de uso do solo, bem como para caracterização e diagnóstico da população residente na área de estudo.

Para a realização do estudo da ocupação ao longo de trinta e cinco anos, realizou-se processamento digital das imagens com o software $\mathrm{ENVI}^{\circledR} 4.7$, obtendo-se os mapas de uso e ocupação do solo. Em ambiente SIG, realizou-se o processamento a fim de mapear as Áreas de Preservação Permanente (APP's) conforme o Código Florestal Brasileiro, Lei no 12.651/2012 (BRASIL, 2012). Integraram-se os dados supracitados para identificar áreas conflitantes com o Código Florestal. Após, realizou-se diagnóstico populacional com dados advindos do censo do IBGE, utilizando-se software $\operatorname{ArcGis}^{\circledR} 10.1$.

Foram utilizados os satélites Landsat 5 e Landsat 8, obtendo imagens do mapeador temático (TM) referente aos anos 1984, 1993, 2003, 2013, 2017 e 2019. Após a obtenção das imagens, utilizando o software ENVI ${ }^{\circledR} 4.7$, realizou-se o processamento dessas, com a junção das bandas em um único arquivo, efetuando- 
se o recorte da área do estudo e georreferenciando. O mapa na escala 1:5.000.000, referentes a tipologia de solo confeccionados pela Embrapa (2001), fora utilizado para analisar e comparar processos de degradação em cada tipologia de solo de acordo com as ações e atividades realizadas sobre o mesmo. Quanto a determinação das classes e/ou regiões interessadas utilizou-se o Manual Técnico de Uso da Terra do IBGE (2013), baseando-se nas classes de nível II.

O estudo foi realizado no ínterim de 35 anos, tendo como marcos de análise os anos: 1984, 1993, 2003, 2013, 2017 e 2019 para identificação dos usos do solo na presente área. Foram identificadas as seguintes classes temáticas: corpos d'água, agricultura, campo, reflorestamento, floresta nativa, solo exposto e área urbana para a classificação quanto ao uso da terra.

No que diz respeito às nascentes presentes na área de estudo, essas foram mapeadas pela Secretaria de Desenvolvimento Sustentável (SDS) - Governo de Santa Catarina, disponibilizadas em plataforma online. As informações referentes as áreas de risco sujeitas a inundação e deslizamento foram conseguidas junto ao CPRM - Serviço Geológico do Brasil, além das áreas úmidas.

Baseando-se nas correlações das variáveis com padrões diversos, utilizou-se o modelo classificatório da Distância Mahalanobis, que possibilita interferir na identificação das classes pretendidas (OLIVEIRA et al., 2013). Sendo assim definidas, realiza-se o enquadramento de cada pixel em uma classe (BECEGATO et al., 2007). A priori, realizou-se o processamento em toda a extensão da bacia hidrográfica e, posteriormente, nas APP's em torno de nascentes e corpos d'água para analisar as possíveis inconsistências, conforme determina o Código Florestal, Lei no 12.651/2012.

Para extração automática da bacia, fez-se a composição de um mosaico das ortofotos e do MDT, sobrepôs-se a rede hidrográfica, identificou-se as APP's, sendo possível fazer a comparação ao longo dos 35 anos de estudo. Conforme disposto no Código Florestal, Lei no 12.651 de 2012, considerou-se a faixa de 30 metros ao longo das margens dos rios com largura de até 10 metros e 50 metros ao redor de nascentes, caracterizando, assim, as APP's da bacia hidrográfica.

A declividade foi gerada no $\operatorname{ArcGis}^{\circledR}$ 10.1., cuja classificação seguiu a metodologia proposta por Ross (1994). As classes de declividade forte e muito forte não são recomendadas para a urbanização, sendo, portanto, aquelas acima de $20 \%$. Para se obter a validação dos mapas e dados gerados, realizaram-se visitas a campo, coleta de imagens com drone, coordenadas geográficas de pontos estratégicos e imagens de satélite do Google Earth.

Elaborou-se um diagnóstico, nas dimensões do meio biofísico e antrópico, das ações humanas que comprometem a integridade do meio ambiente, elencando os problemas que afetam diretamente a qualidade de vida da população residente na área. Sobrepondo-se os planos de informações e análises espaciais, pôde-se avaliar a magnitude e a distribuição espacial dos impactos e sua importância no cenário do estudo. Com dados do Censo Demográfico de 2010 do IBGE, fez-se análise socioeconômica da área em questão. As informações julgadas pertinentes para o estudo foram: número de residências, pessoas por setor e renda per capita.

Foram analisadas as áreas propícias à urbanização e aquelas sensíveis, como as nascentes, matas 
ciliares, áreas úmidas, com suscetibilidade a movimentos de massa e inundação, bem como as com declividade.

\section{RESULTADOS}

Os resultados obtidos estão expressos na Tabela 1, em percentagem da área total da bacia hidrográfica do rio Ponte Grande (2.722,35 ha.).

Ressalta-se que o estudo entre os anos de 1984 até 2013 foi elaborado por Oliveira (2015). A atualização e análise dos dados e mapas referem-se aos anos de 2017 e 2019.

Tabela 1: Classes de uso do solo da bacia hidrográfica do rio Ponte Grande - Lages/ SC.

\begin{tabular}{lllllll} 
Classes (\%) & $\mathbf{1 9 8 4}(*)$ & $\mathbf{1 9 9 3}(*)$ & $\mathbf{2 0 0 3}(*)$ & $\mathbf{2 0 1 3}(*)$ & $\mathbf{2 0 1 7}$ & $\mathbf{2 0 1 9}$ \\
\hline Agricultura & 3,48 & 5,61 & 7,63 & 6,59 & 7,47 & 0,00 \\
\hline Água & 0,06 & 0,11 & 0,48 & 0,58 & 4,82 & 2,91 \\
\hline Área urbana & 16,55 & 26,51 & 34,92 & 36,8 & 39,64 & 41,73 \\
\hline Campo & 70,08 & 60,25 & 44,84 & 34,27 & 21,96 & 31,38 \\
\hline Mata nativa & 9,65 & 7,21 & 10,69 & 16,75 & 1,10 & 8,68 \\
\hline Reflorestamento & 0,18 & 0,31 & 1,76 & 5,38 & 4,08 & 5,32 \\
\hline Solo exposto & - & - & - & - & 20,89 & 9,98 \\
\hline Total & 100 & 100 & 100 & 100 & 100 & 100
\end{tabular}

Fonte: Oliveira $(* 2015)$.

Cotejando-se os dados da Tabela 1 verifica-se um decréscimo da área de campo ao longo dos anos, de $70 \%$ para $21,9 \%$, em 2017 . Além disso, como fator importante de discussão, ressalta-se o aumento nas áreas de reflorestamento, sendo essas utilizadas para fins econômicos, indo de 0,18\% em 1984 para 5,32\% em 2019. Até o ano de 2003 a maior ocupação do solo era por campo. A partir de 2013 vê-se uma inversão, tendo a urbanização um crescimento superior e perpassando a área de campo, sendo 36,8\% da área total da bacia em 2013, 39,64\% em 2017 e 41,73\% em 2019.
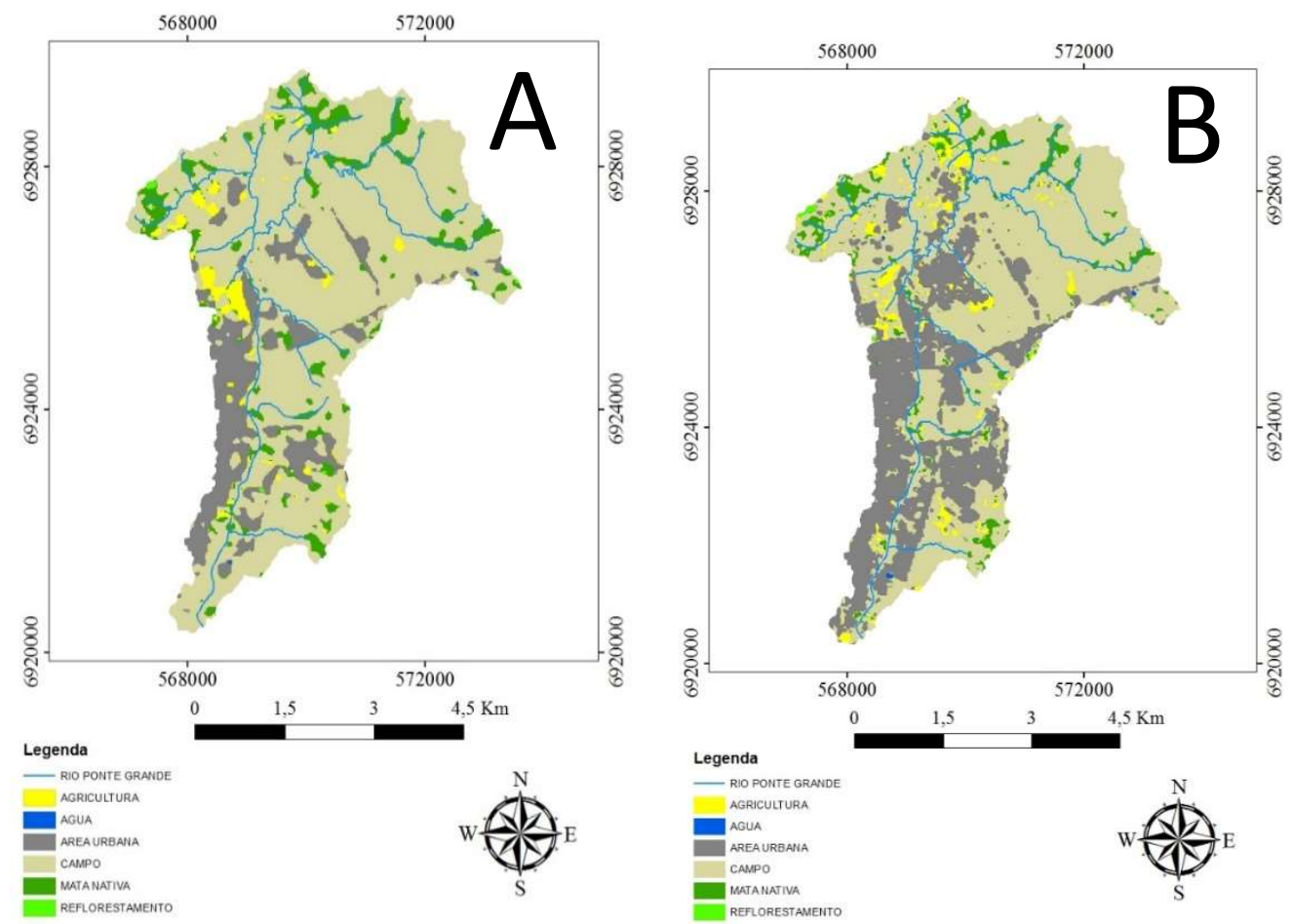

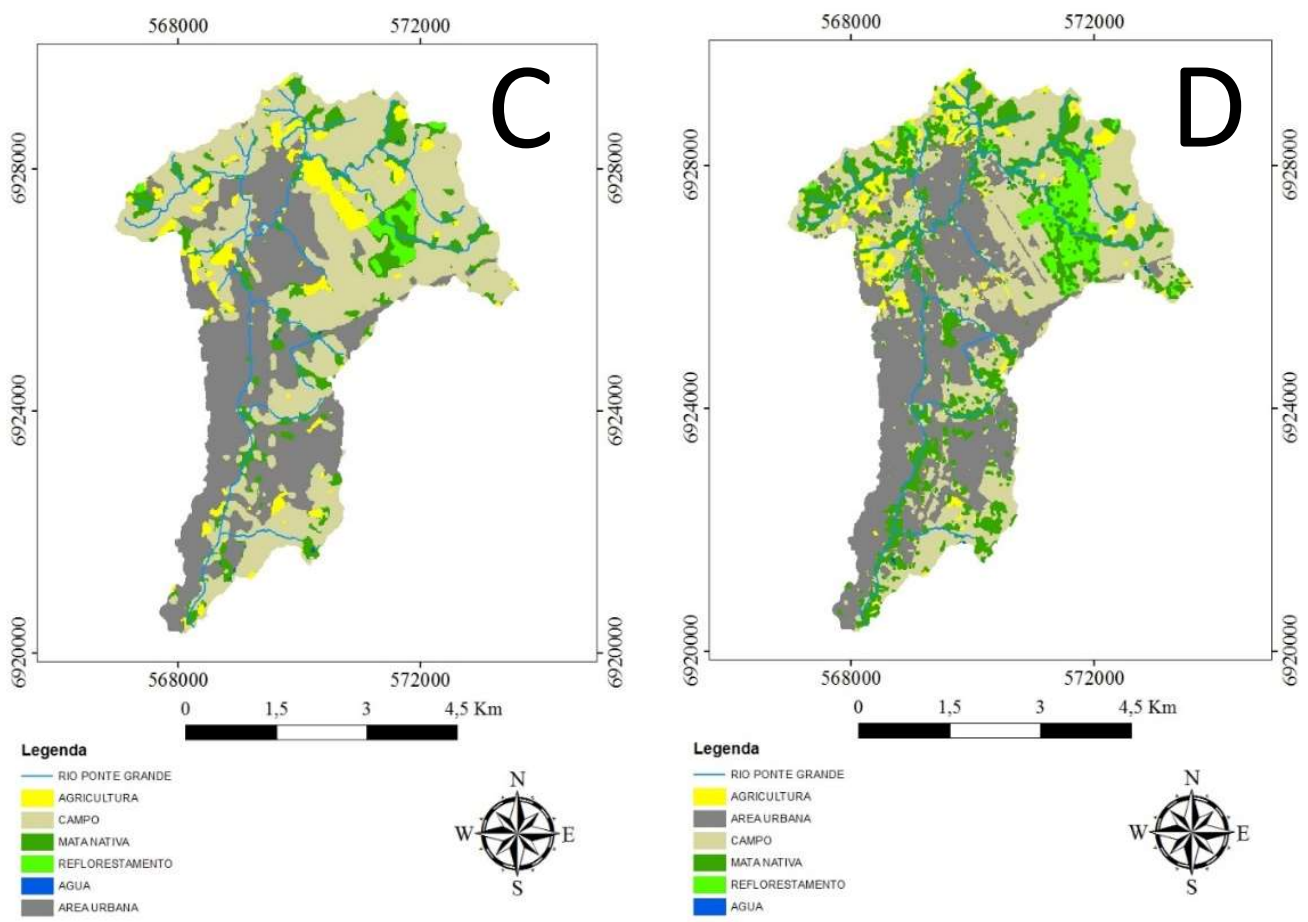

Figura 2: Mapas de uso e ocupação do solo da bacia hidrográfica do rio Ponte Grande, referente aos anos: 1984 (A), 1993 (B), 2003 (C) e 2013 (D), confeccionados a partir de imagens de satélites Landsat-5 e Landsat-8. Fonte: Oliveira (2015).

O decréscimo nas áreas de floresta e de campo nativo estão intimamente interligados com o aumento da área urbanizada. Junto a isso, percebe-se um acréscimo na área de agricultura indo de 3,48\% em 1984, para 7,47\% em 2017, seguida de um decréscimo que praticamente anulou a área destinada a essa atividade em 2019. Em estudo realizado por Oliveira (2015), a autora apresentou mapas (Figura 2) com o uso e ocupação da terra na bacia hidrográfica do rio Ponte Grande ao longo dos anos, demonstrando quais as classes de solo mais atingidas pela urbanização.

Partindo desses dados iniciais, confeccionou-se mapa de uso e ocupação da terra para os anos 2017 e 2019 (Figuras 3 e 4) utilizando a classificação supervisionada para realizar a distribuição espacial dos tipos de solo, sendo esse método de distância denominado de Mahalanobis. O presente método é comumente utilizado e em estudo realizado por Cattani et al. (2013), demonstrou-se que a classificação supervisionada, utilizando o software $\mathrm{ENVI}^{\circledR} 4.5$, apresenta-se como uma opção com alto grau de confiabilidade.

Remetendo os dados e imagens apresentados aos anos de 2017 (Figura 3) e 2019 (Figura 4), tem-se para efeito comparativo os dados do trabalho apresentado por Oliveira (2015), conforme exposto na Figura 2. A mancha urbana, demonstrada nas imagens com a cor cinza, ganha cada vez mais espaço, transformando o ambiente em área urbana consolidada.

Após análise do território, realizou-se diagnóstico social na bacia, a partir de dados do IBGE, com as variáveis VR e VP que correspondem respectivamente a renda e ao número de pessoas por setor censitário. Para tanto, utilizou-se a ferramenta 'selecionar por localização' disponível no software ArcGis $^{\circledR}$ 10.3, fazendo a intersecção de dados entre a bacia hidrográfica e os setores e, em seguida, inserindo as edificações nos mesmos para posterior análise. 

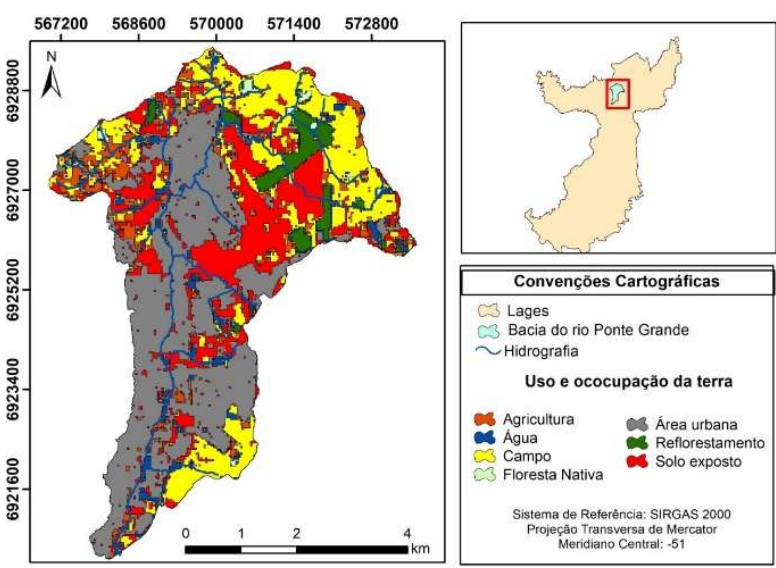

Figura 3: Uso e ocupação do solo baseado na interpretação de imagens de satélite - Landsat 8, do ano de 2017, da bacia hidrográfica do rio Ponte Grande, Lages-SC.
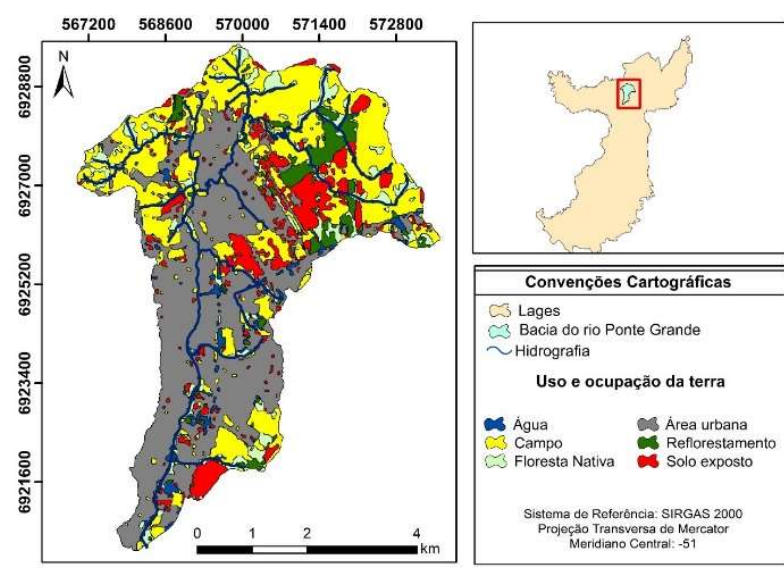

Figura 4: Uso do solo baseado na interpretação de imagens - Landsat 8, ano de 2019, da bacia hidrográfica do rio Ponte Grande, Lages-SC.

Desenvolvendo os dados do IBGE, observa-se que a renda nominal per capta mensal da maior parcela da população residente na bacia hidrográfica do rio Ponte Grande manteve-se entre $1 / 4$ até 2 salários mínimos, conforme sintetizado e demonstrado na Figura 9.

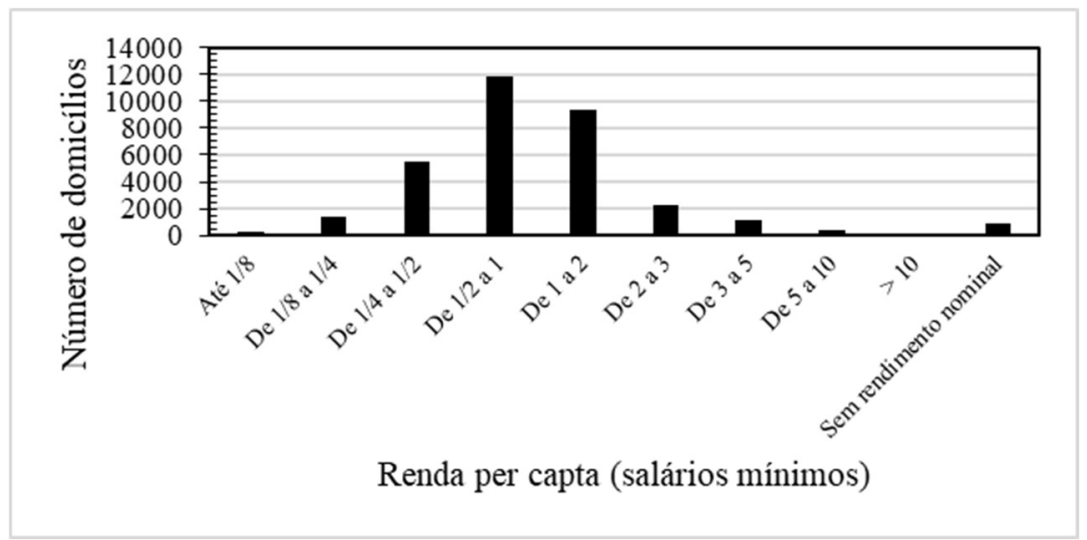

Figura 9: Gráfico da renda per capta dos moradores da bacia hidrográfica do rio Ponte Grande.

\section{DISCUSSÃO}

No estudo realizado por Oliveira (2015) não foram destacadas as áreas de solo exposto, mas resolveu-se por trazer para a análise dos anos 2017 e 2019, pois é possível identificar uma grande área dessa classe e isso demonstra a antropização de diversas formas: corte de plantio/vegetação, aterro para loteamentos e construções, abertura de estradas e acessos.

Pode-se verificar uma abrangente área pertencente a essa classificação no ano de 2017 e isso se deu em razão da estruturação de loteamentos na área da bacia hidrográfica do rio Ponte Grande. Contrastando com a imagem de 2019, é possível identificar a substituição de solo exposto por, principalmente, campo e urbanização, tendo sido o solo ocupado por edificações e infraestrutura ou pelo crescimento de vegetação em solo não ocupado.

Em 2013, a região noroeste, pertencente ao bairro Jardim Celina, era composta principalmente por agricultura, campo e reflorestamento. Porém, em 2017 é possível identificar a substituição de grande parte 
dessa área por solo exposto. Em 2019, a mesma região é classificada principalmente por campo, mas visualmente identifica-se colheita e crescimento de vegetação no local. Isso caracteriza ação antrópica constante, com mudança na utilização do solo.

A região do meio leste, condizente ao bairro Vila Mariza e da Bates, classifica-se como solo exposto em 2017 e em 2019 identifica-se a substituição dessa classe por área urbana, principalmente. A referida área está em constante expansão, com novos loteamentos e condomínios, caracterizando o vetor de crescimento urbano.

A região nordeste é onde a maioria das nascentes da bacia hidrográfica está; dita região de cabeceira. A presente encontra-se prioritariamente preservada, porém o crescimento da área urbana começa a se dar para essa direção, que deve ser preservada. Já na região sudeste, a área que era maioritariamente campo começa a receber impacto antrópico e identifica-se a substituição dessa classe por solo exposto e reflorestamento.

Após observação dos quantitativos de cada classe de solo ao longo dos 35 anos de estudo, é nítida a interferência antrópica em toda a extensão da bacia hidrográfica, provocando inúmeras transformações na ocupação do solo. Em toda a extensão da bacia hidrográfica é possível identificar a área urbana em margens de corpos hídricos e a referida cresce constantemente e em ritmo acelerado, estando em áreas de APP, sem respeito às legislações e ao meio. É perceptível, após análise dos dados e imagens, a substituição de campo, principalmente, pela expansão urbana e reflorestamento. O mesmo acontece com a classe solo exposto, sendo substituído por reflorestamento e, principalmente, pela urbanização.

Diversos são os casos de constatação na substituição de outras classes por, prioritariamente, reflorestamento e área com ocupação urbana, visto que ambas são fruto da antropização para fins comerciais e de moradia. Luiz et al. (2019) constatou, após analisar o uso da terra em Minas Gerais, que as classes que predominantemente cresceram ao longo dos anos na região de estudo foram a de reflorestamento e a área urbana. Resultados semelhantes foram conseguidos em Bauru, São Paulo, em análise realizada por Marchiori et al. (2018). Em estudo de Altmann et al. (2009) fora observado que a evolução do uso e ocupação do solo gera um aumento na área urbana. O mesmo fora constatado por Eckhard et al. (2013) no município de Bom Retiro do Sul, Rio Grande do Sul, com alargamento de 132,57\% da área urbanizada.

A bacia hidrográfica objeto desse estudo possuí área total de $27,2235 \mathrm{~km}^{2}$, sendo que dessa, 2,4424 $\mathrm{km}^{2}$ são Áreas de Preservação Permanente. Ao analisar o desenvolvimento da área com o passar dos anos, verifica-se que não há preservação das áreas destinadas a resguardo, estando essas pressionadas pela ocupação urbana. Atualmente tem-se algumas porções de corpos hídricos preservados, em região de cabeceira e com área reduzida, comparando-se a extensão total da bacia. Mas, ressalta-se que é possível identificar a presença de residências e a não preservação de nascentes e mata ciliares nessa região, comprometendo a qualidade dos cursos d'água. Observa-se a presença de reflorestamento para fins comerciais em grande extensão, inclusive em áreas destinadas a preservação. 


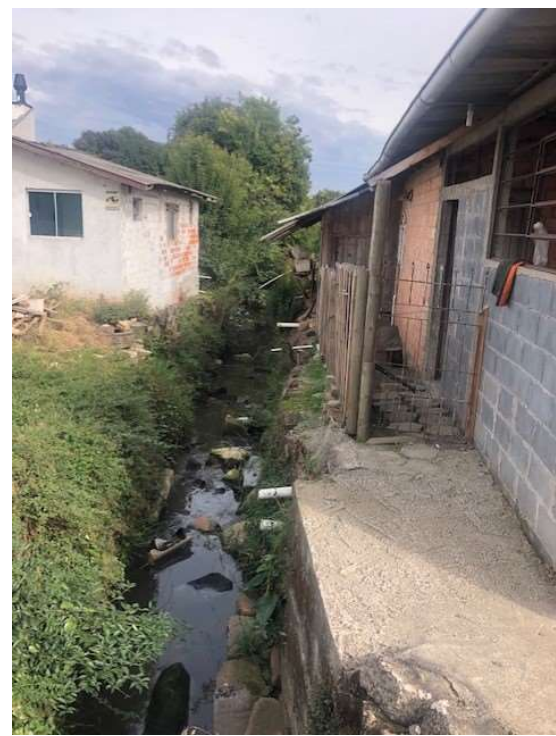

Figura 5: Ocupação consolidada em córrego afluente do rio Ponte Grande.

Nota-se que as áreas que permanecem intactas e conservadas estão em áreas com alta declividade, como os topos de morro. Conforme exposto em estudo realizado por Coutinho et al. (2013), as áreas com alta declividade permanecem prioritariamente conservadas em razão do relevo montanhoso e da dificuldade de ocupar. No que diz respeito às áreas centrais e a jusante do curso hídrico principal, essas se apresentam consolidadas, com residências em grande parte da extensão, não sendo resguardadas as áreas destinadas a preservação, comprometendo a qualidade da água e, consequentemente, a qualidade de vida da população ali residente, conforme exposto na Figura 5, onde se vislumbram residências adjacentes ao córrego, além de despejos irregulares de esgoto doméstico.

A redução das APP's é perceptível e trazida em estudos de Schneider et al. (2016) e Borges et al. (2017), devido a interferência antrópica e que reflete diretamente na redução das áreas protegidas ao longo dos cursos d'água, afetando no controle de processos erosivos e de enchentes. A ocupação de APP's contraria ao exposto na legislação ambiental e torna as ocupações ilegais (RIFFO et al., 2000).

No que diz respeito às áreas de risco, há prevalência da extensão da bacia hidrográfica do rio Ponte Grande em área com suscetibilidade muito alta à inundação, contabilizando 1313 edificações, sendo residências e estabelecimentos, conforme descrito em estudo realizado pelo Serviço Geológico do Brasil CPRM, em 2018.

As ocupações de áreas marginais e de várzeas resultam em fenômenos climáticos que ocasionam problemas à população, como a inundação. $O$ agravamento se dá em razão da retirada da vegetação ciliar, depósito irregular de lixo e alta impermeabilização da bacia (OLIVEIRA, 2010).

O aumento do nível da água das bacias hidrográficas, além da vazão normal, transbordando da calha dos corpos hídricos sobre as áreas circunvizinhas é denominado de inundação, e essas são geradas pela combinação de fatores como volumes pluviométricos extremos, tipos de solo, declividade do terreno, fatores físicos e antropização (CASTRO, 2003; MAKRAKIS, 2017).

A Figura 6 demonstra a setorização feita pelo CPRM, indicando as áreas de alto e muito alto risco no município de Lages. A bacia hidrográfica do rio Ponte Grande foi destacada pela própria autora para 
identificação espacial.

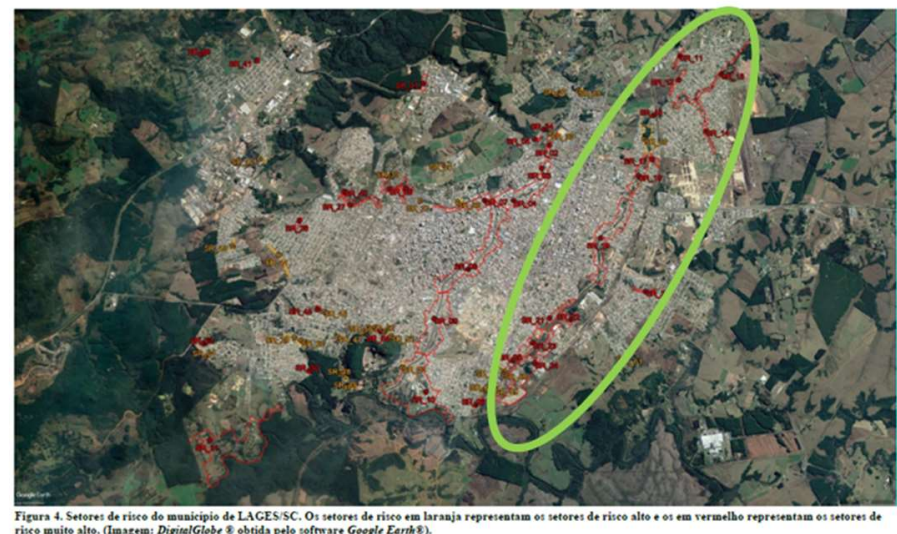

Figura 6: Mapa da setorização dos locais de risco alto e risco muito alto na bacia do rio Ponte Grande-Lages-SC. Fonte: Adaptado do Serviço Geológico do Brasil (2018).

Em estudos realizados por Rafaeli Neto et al. (2015) e Makrakis (2017) são apresentadas as fragilidades da bacia hidrográfica do Rio Ponte Grande quanto a ocorrência de inundação, sendo esse fenômeno cada vez mais frequente na área. Na Figura 7 é demonstrada área inundada em evento climático registrado em 2017.

Conforme registro no Formulário de Informação de Desastre - FIDE, na plataforma digital do Sistema Integrado de Informações de Desastres - S2iD, sendo esses pertencentes ao Sistema Nacional de Proteção e Defesa Civil, verifica-se a ocorrência do fenômeno inundação no município de Lages em diversos anos: 2019, 2017, 2013, 2011, 2008, 2005, 2004, 2001, 2000, 1998, 1993, 1992, 1989, 1983, 1981, 1980, 1979 (BRASIL, 2020). Com relação a suscetibilidade a movimentação de massa, tem-se poucas áreas localizadas nessas regiões e nenhuma residência inseridas nas mesmas.

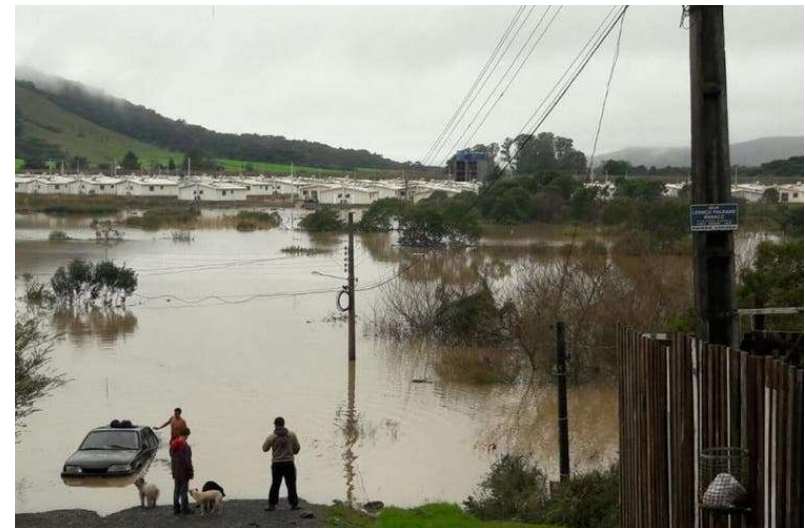

Figura 7: Área inundada no bairro da Várzea, bacia hidrográfica do rio Ponte Grande, Lages-SC em 2017. Fonte: Lages (2017).

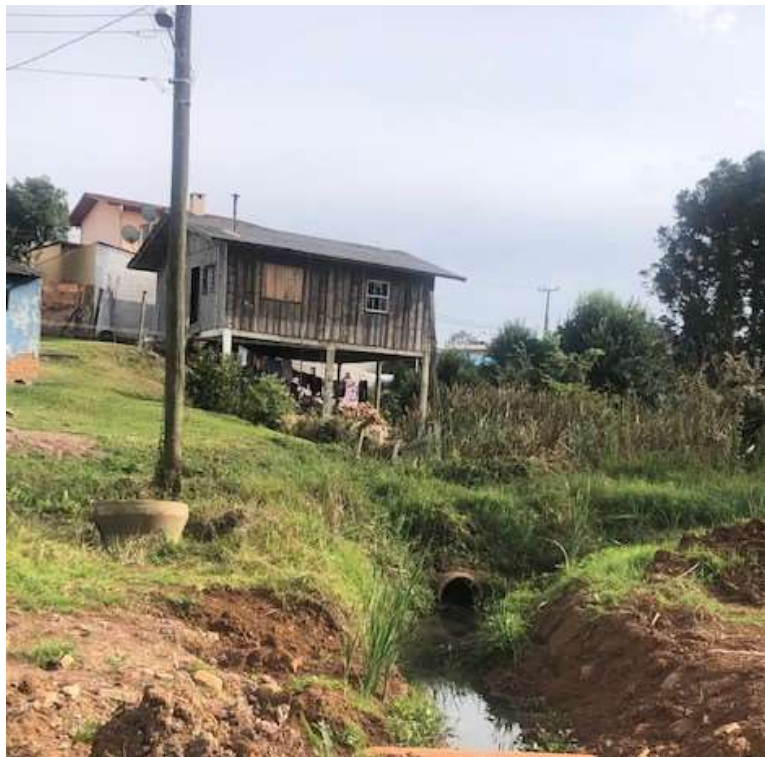

Figura 86: Despejo irregular de esgoto doméstico.

A bacia hidrográfica do rio Ponte Grande está urbanizada quase que na totalidade, restando poucos espaços preservados. A alta taxa de ocupação com 30.548 edificações, impacta na queda na qualidade de vida das pessoas, pois os aglomerados urbanos geram uma grande quantidade de resíduos, sendo muitos 
despejados de forma irregular em córregos (Figura 8) e terrenos, precariedade nas ligações de água pluvial, rede de esgoto e coleta seletiva.

Em estudo realizado por Lavnitcki (2018) quanto à qualidade da água na bacia hidrográfica do Rio Ponte Grande, constatou-se que o referido corpo hídrico foi enquadrado como Classe IV, de acordo com a Resolução CONAMA no 357/2005. Isso significa que há alteração nas características físico-químicas, principalmente próximas à urbanização, derivada de lançamentos de efluentes domésticos, disposição de resíduos e escoamento superficial de águas pluviais.

Em estudo realizado por Santolin (2009), verifica-se relação entre a baixa renda com o nível de escolaridade, tendo salários mais baixos aqueles menos escolarizados.

A bacia hidrográfica do rio Ponte Grande é habitada principalmente por pessoas de baixa renda e isso influencia diretamente na qualidade das edificações, pois o acesso ao mercado imobiliário formal é restrito, provocando o fenômeno de autoconstrução ou construção espontânea. Esse é a composição de duas ou mais residências no mesmo lote, sem planejamento adequado e sem respeito aos preceitos trazidos no plano diretor, influenciando em problemas que vão muito além da precariedade das edificações, como falta de iluminação e ventilação entre as habitações (CARVALHO et al., 2015).

A renda per capta é relacionada diretamente com a questão habitacional, mas também com o nível de escolaridade e instrução da população e, esses, influenciam na consciência ambiental dessa. É indiscutível a ligação existente entre a escolaridade e a condição socioeconômica, visto que muitas pessoas abandonam os estudos para auxiliar no sustento da família. As fragilidades financeiras e educacionais impactam na dificuldade econômico-social dessas pessoas (SCARPELLINI, 2011).

Diante da análise dos dados sociais, verifica-se a vulnerabilidade dos residentes na bacia objeto do presente estudo, pois além do impasse financeiro, muitas dessas pessoas estão expostas a desastres naturais, edificações precárias e condições insalubres de moradia.

Percebe-se que a precariedade dessas habitações influencia diretamente na condição de saúde e de bem-estar das pessoas, estando essas expostas a patologias e riscos, tornando necessária a implantação de medidas públicas que revertam tal situação e garantam uma condição mínima de habitação.

\section{CONCLUSÕES}

Ao longo de 35 anos, verifica-se que a antropização alterou e segue alterando o uso e ocupação do solo da bacia hidrográfica do rio Ponte Grande, com a área urbana sendo a classe prioritariamente identificada. Perceptível, também, a falta de preservação das APP's, estando essas pressionadas pelo desenvolvimento urbano e, em grande extensão, utilizadas como reflorestamento para fins comerciais. Apenas algumas pequenas porções de APP encontram-se preservadas estando essas em regiões de cabeceiras e em áreas com alta declividade.

A alta taxa de ocupação da referida bacia é reflexo da impossibilidade de aquisição de melhores áreas destinadas a moradia, de uma população vulnerável economicamente e ambientalmente. A maioria da população residente está exposta a edificações precárias, carência de saneamento básico, precariedade no 
acesso a coleta de resíduos e suscetibilidade a desastres ambientais hídricos. Das mais de 90 mil pessoas que habitam na bacia hidrográfica, pouco mais de 11 mil possuem renda per capta de $1 / 2$ a 1 salário mínimo.

Ressalta-se que há forte tendência ao crescimento da cidade se dar em direção às áreas ainda preservadas da bacia. Porém, necessita-se frear a expansão urbana em áreas sensíveis, como áreas de risco e APP's, para que os problemas sofridos por moradores dessa região não estejam mais expostos a problemas sociais, ambientais e habitacionais. Assim, o vetor de crescimento torna-se crítico e preocupante, necessitando de medidas públicas para coibir tal degradação.

\section{REFERÊNCIAS}

ALMEIDA, A. Q.. Influência do desmatamento na disponibilidade hídrica da bacia hidrográfica do córrego do Galo, Domingos Martins, ES. Dissertação (Mestrado em Engenharia Ambiental) - Universidade Federal do Espírito Santo, Vitória, 2007.

ALTMANN, A. L.; ECKHARDT, R. R.; REMPEL, C.. Evolução temporal do uso e cobertura da terra - estudo de caso no município de Teutônia - RS, Brasil. Revista Brasileira de Cartografia, v.61, n.3, p.273-283, 2009.

ALVARES, C. A.; STAPE, J. L.; SENTELHAS, P. C.; GONÇALVES, J. L. M.; SPAROVEK, G.. Köppen's climate classification map for Brazil. Meteorologische Zeitschrift, v.22, n.6, p.711-728, 2013.

ALVES, R. E.. Caracterização da fisionomia da paisagem a partir da fragilidade ambiental da bacia hidrográfica do Ribeirão da Picada, Jataí/GO. Dissertação (Mestrado em Geografia) - Universidade Federal de Goiás, Jataí, 2012.

BECEGATO, V. A.; FERREIRA, F. J. F.; CABRAL, J. B. P.; FIGUEIREDO, O. A. R.; NETO, S. L. R.. Monitoramento do uso e ocupação do solo em área de influência do município de Fazenda Rio Grande - Região metropolitana de Curitiba-PR. RA'E GA, Curitiba, n.14, p.217-226, 2007.

BONTEMPS, S.; HEROLD, M.; KOOISTRA, L.; VAN GROENESTIJN, A.; HARTLEY, A.; ARINO, O.. Revisiting land cover observation to address the needs of the climate modeling community. Biogeosciences, v.9, p.2145-2157. 2012.

BORGES, L. A. C.; MORAS FILHO, L. O.; MARQUES, R. T.; SILVA, C. C.; SILVA, L. G. P.. A influência do tamanho do imóvel rural sobre as áreas de preservação permanente de corpos d'água. Caminhos de Geografia, v.18, n.64, p.444453, 2017.

BRASIL. Sistema Integrado de Informações sobe Desastres. Registro e Reconhecimento. Brasília: S2iD, 2020.

BRASIL. Lei n. 12.651, de 25 de maio de 2012. Institui o novo Código Florestal Brasileiro. Brasília: DOU, 2012.

BRASIL. Ministério de Minas e Energia. Secretaria de Geologia, Mineração e Transformação Mineral. Serviço Geológico do Brasil - CPRM. Setorização de áreas de alto e muito alto risco a movimentos de massa, enchentes e inundações. Lages, 2018.
CÂMARA, G.; DAVIS, C.. Introdução. In: CÂMARA, G.; DAVIS, C.; MONTEIRO, A. M. V.. Introdução à ciência da geoinformação. São José dos Campos: INPE, 2001.

CAMPOS, C. G. C.; CARDOSO, J. T.; LEMOS, M. R.; SCHIER, D. T.. Estudo sobre a influência de variáveis meteorológicas nos casos de acidentes por animais peçonhentos em Lages/SC.

Hygeia: Revista Brasileira de Geografia Médica e da Saúde, v.15, n.31, p.43-55, 2019. DOI:

https://doi.org/10.14393/Hygeia153146311

CARVALHO, N. C.; GUIMARÃES, M. G.; CASTILLO, L. A. G. Desenvolvimento de alternativas sustentáveis para habitação de baixa renda. Estudos em Design, v.18, n.2, 2015.

CASTRO, A. L. C.. Manual de desastres: desastres naturais. Brasília: Ministério da Integração Nacional, 2003.

CATTANI, C. E. V.; MERCANTE, E.; SOUZA, C. H. W.; WRUBLACK, S. C.. Desempenho de algoritmos de classificação supervisionada para imagens dos satélites RapidEye. In: SIMPÓSIO BRASILEIRO DE SENSORIAMENTO REMOTO - SBSR, 16. Anais. Foz do Iguaçu: INPE, 2013. p.6.

CHEN, X.; ZHAO, H. M.; LI, P. X.; YIN, Z. Y.. Remote sensing image-based analysis of the relationship between urban heat island and land use/cover changes. Remote Sensing of Environment, v.104, p.133-146, 2006. DOI: https://doi.org/10.1016/j.rse.2005.11.016

COUTINHO, L. M.; ZANETTI, S. S.; CECILIO, R. A.; GARCIA, G. O.; XAVIER, A. C.. Usos da terra e Áreas de Preservação Permanente (APP) na Bacia do Rio da Prata, Castelo-ES. Floresta Ambient., Seropédica, v.20, n.4, p.425-434, 2013. DOI: https://doi.org/10.4322/floram.2013.043

CORDEIRO, L. M. M.; ALMEIDA, N. A.; MELO, E. E. C.; SOUZA, Y. I. F.. Diagnóstico geoambiental da microbacia hidrográfica do riacho Santa Luiza no município de Soledade/PB. In: CONGRESSO BRASILEIRO DE CARTOGRAFIA. Anais. Gramado, 2014. p.14.

CORONA, P.. Consolidating new paradigms in large scale monitoring and assessment of forest ecosystems. Environmental Research, v.144, p.8-14, 2016.

CUNHA, S. B.; GUERRA, A. J. T.. Impactos ambientais urbanos no Brasil. 8 ed. Rio de Janeiro: Bertrand Brasil, 2011. 
ECKHARDT, R. R.; SILVEIRA, C. A.; REMPEL, C.. Evolução temporal do uso e cobertura da terra no município de Bom Retiro do Sul - RS - BRASIL. Caminhos de Geografia, v.14, n.47. p.150-161, 2013.

ELLIS, E. C.; KAPLAN, J. O.; FULLER, D. Q.; VAVRUS, S.; GOLDEWIJK, K. K.; VERBURG, P. H.. Used planet: a global history. Proceedings of the National Academy of Sciences of the United States of America, v.110, p.7978-7985, 2013.

EMBRAPA. Empresa Brasileira de Pesquisa Agropecuária. Mapa de Solos do Brasil: Escala 1:5.000.000. Rio de Janeiro: IBGE, 2001.

FACCINI, F.; LUINO, F.; PALIAGA, G.; SACCHINI, A.; TURCONI, L.; JONG, C.. Role of rainfall intensity and urban sprawl in the 2014 flash flood in Genoa City, Bisagno catchment (Liguria, Italy). Applied Geography, v.98, p.224-241, 2018. DOI: https://doi.org/10.1016/j.apgeog.2018.07.022

FRANZONI, A. M. B.; SUFFI, S.. Geoprocessamento uma Técnica para Desenvolvimento Sustentável. In: SIMPÓSIO SOBRE MEIO AMBIENTE, 10. Anais. Niterói: UNIVERSO, 2002.

GARZUZI, J.; GOLDSHLEGER, N.; BEN-DOR, E.; ASAF, L.; BENYAMIN, R.. Impacts of land use on quantity and quality of urban runoff (Herzliya and Ra'anana case study). International Archives of the Photogrammetry. Remote Sensing and Spatial Information Sciences, Haifa, v.38, p4-82-W9, 2010

GRECCHI, R. C.; GWYN, Q. H. J.; BÉNIÉ G. B.; FORMAGGIO, A. R.; FAHL, F. C.. Land use and land cover changes in the Brazilian Cerrado: A multidisciplinary approach to assess the impacts of agricultural expansion. Applied Geography, v.55, p.300-312, 2014. https://doi.org/10.1016/i.apgeog.2014.09.014

IBGE. Instituto Brasileiro de Geografia e Estatística. Base de informações do censo demográfico 2010: Resultados do Universo por setor censitário. Rio de Janeiro: IBGE, 2011.

IBGE. Instituto Brasileiro de Geografia e Estatística. Manual técnico do uso da terra. 3 ed. Rio de Janeiro: IBGE, 2013.

IBGE. Instituto Brasileiro de Geografia e Estatística. IBGE Cidades: Lages. Lages: IBGE, 2018.

LAGES. Coordenadoria Municipal de Proteção e Defesa Civil de Lages. Relatório de inundação 2017. Lages, 2017.

LAVNITCHI, L.. Avaliação da qualidade da água superficial e sedimentos da bacia hidrográfica do Rio Ponte Grande no município de Lages/ SC. Dissertação (Mestrado em Ciências Ambientais) - Universidade do Estado de Santa Catarina, Lages, 2018.

LAMCHIN, M.; LEE, J. Y.; LEE, W. K.; LEE, E. J.; KIM, M.; LIM, C.; $\mathrm{CHOI}, \mathrm{H}$.; KIM, S.. Assessment of land cover change and desertification using remote sensing technology in a local region of Mongolia. Advances in Space Research, v.57, p.6477, 2016.

LIMA, E. P.; SEDIYAMA, G. C.; ANDRADE, R. G.; LOPES, V. D.; SILVA, B. B.. Evapotranspiração real diária em sub-bacias do Paracatu, utilizando produtos do sensor Modis. Rev. Ceres,
Viçosa, v.61, n.1, p.017-027, 2014.

LU, M.; CHEN, J.; TANG, H.; RAO, Y.; YANG, P.; WU, W.. Land cover change detection by integrating object-based data blending model of Landsat and MODIS. Remote Sensing of Environment., v.184, p.374-386, 2016.

LUIZ, C. H. P.; FARIA, S. D.; ESCADA, M. I.. Modelagem da expansão do reflorestamento com eucalipto e efeitos na estrutura da paisagem. Mercator,

Fortaleza, v.18, p.18019, 2019. DOI:

https://doi.org/10.4215/rm2019.e18019

MACEDO, D. R.; HUGHES, R. M.; KAUFMANN, P. R.; CALLISTO, M.. Development and validation of an environmental fragility index (EFI) for the neotropical savannah biome. Science of the Total Environment, v.635, p.1267-1279, 2018. DOI:

http://doi.org/10.1016/j.scitotenv.2018.04.216

MAKRAKIS, M. C.. Mapeamento e análise das áreas suscetíveis a inundações no município de Lages-SC. Dissertação (Mestrado em Sensoriamento Remoto) Universidade Federal do Rio Grande do Sul, Porto Alegra, 2017.

MARCHETTI, M.; VIZZARRI, M.; LASSERRE, B.; SALLUSTIO, L.; TAVONE, A.. Natural capital and bioeconomy: challenges and opportunities for forestry. Annals of Silvicultural Research, v.38, p.62-73, 2014

MARCHIORI, L. M.; SARTORI, A. A. C.; OLMEDO, J. P.; GUERREIRO, S. F.. Dinâmica espaço-temporal da expansão urbana de Bauru/SP. Revista Ibero Americana de Ciências Ambientais, v.9, n.3, p.354-364, 2018. DOI: http://doi.org/10.6008/CBPC2179-6858.2018.003.0028

MORUZZI, R. B.; PINTO, S. A. F.; ROSSETTI, L. A. F. G.; PEREIRA, L. H. BERMUDEZ, M.; BARBOSA, C.. Contribuição metodológica para a caracterização de áreas potenciais de inundação em uma bacia hidrográfica urbanizada, com o suporte das técnicas de sensoriamento remoto e geoprocessamento: apresentação de dois cenários em um módulo piloto. In: SIMPÓSIO BRASILEIRO DE RECURSOS HÍDRICOS, 17. Anais. São Paulo, 2007.

NASCIMENTO, W. M.; VILAÇA, M. G.. Bacias Hidrográficas: Planejamento e Gerenciamento. Revista eletrônica da Associação dos Geógrafos Brasileiros, Três Lagoas, n.7, p.102-121, 2008.

NEWBOLD, T.; HUDSON, L. N.; HILL, S. L.; CONTU, S.; LYSENKO, I.; SENIOR, R. A.; PURVIS, A.. Global effects of land use on local terrestrial biodiversity. Nature, v.520, p.45-50, 2015.

NOVO, E. M. L. M.. Sensoriamento remoto: princípios e aplicações. 3 ed. São Paulo: Edgard Blucher, 2008.

OLIVEIRA, G. G.. Modelos para previsão, espacialização e análise das áreas inundáveis na bacia hidrográfica do Rio Caí, RS. Dissertação (Mestrado em Sensoriamento Remoto) Universidade Federal do Rio Grande do Sul, Porto Alegre, 2010.

OLIVEIRA, J. C.. Caracterização ambiental da bacia hidrográfica do Rio Ponte Grande no município de Lages- 
SC. Dissertação (Mestrado em Produção Vegetal) Universidade do Estado de Santa Catarina, Lages, 2015

OLIVEIRA, T. C.; SARMIENTO, C. M.; RAMIREZ, M.; SILVA, L. F. L.; MIRANDA, L. H.. Avaliação de métodos de classificação utilizando imagem Landsat-8 no mapeamento de uso e ocupação do solo. In: CONGRESSO BRASILEIRO DE GEOPROCESSAMENTO. Anais. Rio de Janeiro, 2013.

PRINA, B. Z.; MONGUILHOTT, M.. Análise das transformações da paisagem de áreas próximas ao rio Jaguari aplicando técnicas de sensoriamento remoto em imagens do satélite Landsat-5. In: SIMPÓSIO BRASILEIRO DE SENSORIAMENTO REMOTO-SBSR, 15. Anais. Curitiba: INPE, 2011. p.3821.

RAFAELI NETO, S. L.; BECEGATO, V. A.; CABRAL, J. B. P.. Monitoramento da qualidade da água do rio Caveiras no planalto serrano de Santa Catarina com suporte de tecnologias de geomática. Boletim Goiano de Geografia, Goiânia, v.33, n.1, p.27-46, 2013. DOI: https://doi.org/10.5216/bgg.v33i1.23629

RAFAELI NETO, S. L.; RICARDO, G. S.; MENDES, C. F.; CUNHA, M. B.. Modelagem hidráulica dos eventos de inundação em Lages (SC). In: CONGRESSO BRASILEIRO DE GESTÃO AMBIENTAL, 6. Anais. Porto Alegre, 2015.

RIFFO, R.; VILLARROEL, C.. Caracterización de la flora y fauna Del humedal Los Batros, comuna de San Pedro de la Paz. Gayana, v.64, p.23-37, 2000.

ROSS, J. L. S.. Análise empírica da fragilidade dos ambientes naturais e antropizados. Revista do Departamento de Geografia, n.8, p.63-74. 1994.

SANTOLIN, R.. Curvas de salários dinâmicas: um estudo determinante da histerese do desemprego no Brasil. Belo Horizonte: UFMG, 2009.

SANTOS, R. F.. Livro: planejamento ambiental: teoria e prática. São Paulo: Oficina de Textos, 2004.
SOUZA, S. O.. Vulnerabilidade ambiental da planície costeira de Caravelas (Bahia): uma proposta geossistêmica. Dissertação (Mestrado em Geografia) - Universidade Federal do Espírito Santo, Vitória, 2013.

SCARPELLINI, M.; VY, C.. Monoparentalidade Feminina e Vulnerabilidade Social: a realidade de mulheres chefes de família no município de Apucarana. In: SIMPÓSIO GÊNERO E POLÍTICAS, 2. Anais. Londrina, 2011.

SCHNEIDER, V. E.; MAGRIN, T. B.; CEMIN, G.; SANTOS, G. M. Análise da situação ambiental das Áreas de Preservação Permanente no município de São José dos Ausentes-RS. Scientia cum Industria, v.4, n.2, p.125-130, 2016

VIEIRA, J. J. A.. Análise comparativa dos métodos de classificação de imagem de alta resolução para mapeamento da cobertura do solo. Monografia (Especialização em Cartografia) - Universidade Federal de Minas Gerais, Belo Horizonte, 2011.

WENG, Q.; QUATTROCHI, D. A.. Thermal remote sensing of urban areas: An introduction to the special issue. Remote Sensing of Environment, v.104, p.119-122, 2006.

YANG, X.; LO, C. P.. Using a time series of satellite imagery to detect land use and land cover changes in the Atlanta, Georgia metropolitan area. International Journal of Remote Sensing, v.23, n.9, p.1775-1798, 2002.

YANG, J.; GONG, P.; FU, R.; ZHANG, M.; CHEN, J.; LIANG, S.; $\mathrm{XU}, \mathrm{B}$.; SHI, J.; DICKINSON, R.. The role of satellite remote sensing in climate change studies. Nature Climate Change, v.3, n.10, p.875-883, 2013.

ZHU, Z.; FU, Y.; WOODCOCK, C. E.; OLOFSSON, P.; VOGELMANN, J. E.; HOLDEN, C.; WANG, M.; DAI, S.; YU, Y.. Including land cover change in analysis of greenness trends using all available Landsat 5, 7, and 8 images: A case study from from Guangzhou, China (2000-2014). Remote Sensing of Environment, v.185, p.243-257, 2016. DOI: https://doi.org/10.1016/j.rse.2016.03.036

A CBPC - Companhia Brasileira de Produção Científica (CNPJ: 11.221.422/0001-03) detém os direitos materiais desta publicação. Os direitos referem-se à publicação do trabalho em qualquer parte do mundo, incluindo os direitos às renovações, expansões e disseminações da contribuição, bem como outros direitos subsidiários. Todos os trabalhos publicados eletronicamente poderão posteriormente ser publicados em coletâneas impressas sob coordenação da Sustenere Publishing, da Companhia Brasileira de Produção Científica e seus parceiros autorizados. Os (as) autores (as) preservam os direitos autorais, mas não têm permissão para a publicação da contribuição em outro meio, impresso ou digital, em português ou em tradução. 